\title{
Development of New Microsatellite (STR) Markers for Montagu's Harrier (Circus pygargus) via 454 Shot-Gun Pyrosequencing
}

\author{
Susann Janowski ${ }^{1, *}$, Markus A. Grohme ${ }^{2}$, Marcus Frohme ${ }^{2}$ and Michael Wink ${ }^{1}$ \\ ${ }^{1}$ Institute of Pharmacy and Molecular Biotechnology, Department Biology, Heidelberg University, Im Neuenheimer \\ Feld 364, 69120 Heidelberg, Germany; ${ }^{2}$ Molecular Biotechnology and Functional Genomics, Technical University of \\ Applied Sciences, Hochschulring 1, 15745 Wildau, Germany
}

\begin{abstract}
During the last decades the ground-breeding Montagu's harrier (Circus pygargus, Linnaeus, 1758) has changed its breeding habitats in Europe to agricultural areas in which many local populations would be close to extinction without a special nest protection regime. Although Montagu's harrier is a well-studied species in terms of ecology and breeding biology, its genetic structure and population genetics are almost unknown. As there is a lack of good genetic markers we developed a set of 19 microsatellite markers comprising 16 new STR markers which were identified by next-generation sequencing (NGS) using 454 shot-gun pyrosequencing of genomic DNA. The STR markers were arranged into three multiplex PCR sets for high throughput genotyping and characterised. The marker set provides a powerful tool for kinship analysis. The combined non-exclusion probability for parent pairs was $1.13 * 10^{-11}$. Only three loci showed PIC values $<0.50$. In total, 121 known family relationships were compared with genetically calculated ones to test the markers suitability for parentage analysis. In $97.5 \%$ of all cases full-sibships were accurately determined and $97.6 \%$ of all mothers were assigned correctly to their chicks. The present multiplex PCR panels can be used to investigate several hypotheses concerning breeding behaviour, kinship, exchange rates between populations and phylogeography.
\end{abstract}

Keywords: Circus pygargus, Dipetalogaster maxima, genotyping, microsatellites, Montagu's harrier, multiplex PCR, next-generation sequencing, parentage analysis.

\section{INTRODUCTION}

Montagu's harrier (Circus pygargus, Linnaeus, 1758) is a well-studied raptor as far as ecological and breeding aspects are concerned. It seems to be one of the more flexible and adaptive raptors in our modern world. Since the beginning of the $20^{\text {th }}$ century this species has changed its favourite breeding habitat from formerly natural wetlands like marshes, lowland and swamps [1-4] to agricultural areas such as grain fields $[5,6]$. This habitat shift took place in the WestEuropean breeding populations in 1990; as a consequence $70-90 \%$ of Montagu's harrier breed in agricultural areas today [7]. According to BirdLife International (2013), the global population of Montagu's harrier consisting of 5075,000 breeding pairs is classified as "least concern". Nevertheless, many European populations of Montagu's harrier suffer significant losses, mainly due to human activities on farmland [8-10]. Without protection, approximately $60 \%$ of nestlings of this ground-breeding bird would be killed during harvest [5]. In Germany, Montagu's harrier mainly chooses wheat and barley fields for breeding, but lucerne (alfalfa) and rye fields are also used [11, 12]. In Germany, as well as in other European countries, these crops are harvested too frequently and very early in the breeding season for silage and biogas production (especially during

*Address correspondence to this author at the Institute of Pharmacy and Molecular Biotechnology, Department Biology, Heidelberg University, Im Neuenheimer Feld 364, 69120 Heidelberg, Germany;

Tel: 0049-6221-54-4847; Fax: 0049-6221-54-4884;

E-mail: Janowski@uni-heidelberg.de
May and beginning of June). Intensive nest protection is usually the only way to enable breeding success $[9,12,13]$. A second critical factor for Montagu's harrier is the continuous decline in prey availability due to the destruction of many suitable hunting grounds, like fallows and field edges $[14,15]$. As a consequence of this fragile situation it will not be possible to protect every small subpopulation of this species. More important might be the protection of very productive and stable breeding populations, that can provide new genotypes for small and declining populations through natal dispersal [7].

Philopatry and natal dispersal as well as survival rates of young and adult Montagu's harriers are poorly investigated and far from being understood. In particular, natal dispersal (the distance from natal sites to areas of first breeding attempt) could be an important parameter for conservation; a high degree of natal dispersal will promote an exchange of individuals between populations and might therefore be an important mechanism for preserving a high genetic variability $[16,17]$. In general, Montagu's harrier does not seem to be as highly philopatric as other raptors [5]. Liminana et al. [18] reviewed the results from five tagging programs in different Spanish regions. From 1,662 juveniles tagged in these programs, only $7 \%$ were observed breeding in the following years. Of those, only $5 \%$ of both sexes were considered philopatric (defined as first breeding attempt closer than $10 \mathrm{~km}$ to the natal site). However, the authors noted that tagging and monitoring at small or medium scale may not be adequate for estimating natal dispersal in this species [18]. Genetic studies could be a better way to understand philopatric behaviour and natal dispersal. 
Genetic analyses of Montagu's harrier are rare. Its phylogenetic position among raptors has been established based on nucleotide sequences of the mitochondrial cytochrome $b$ gene [19]. The only detailed genetic study (of which we are aware) deals with variation of mitochondrial DNA among populations of Montagu's harrier throughout its breeding range [20]. But mtDNA does not provide enough variation to study questions of philopatry and dispersal in detail. However, highly variable microsatellites (Short Tandem Repeats, STR-loci) besides SNPs (single nucleotide polymorphisms) are one of the most useful tools for population genetics [21, $22]$. They could be used for the analysis of a variety of questions, like kinship, family and demographic structure, local genetic diversity as well as connectivity and exchange rates between populations. Such studies can support conservation and management strategies and help to preserve this species in our changing landscape.

In this study we describe the isolation and characterization of 16 novel STR-loci by next-generation sequencing (NGS). Three multiplex PCR sets (comprising 19 STR-loci) were developed which allow the economic analysis of thousands of samples. In order to obtain blood samples from adult Montagu's harrier a blood sucking bug (Dipetalogaster maxima; Heteroptera, Reduviidae) was employed. To demonstrate the suitability of the multiplex PCR set, a parentage analysis was carried out and the results were compared with known data from field studies.

\section{MATERIALS AND METHODS}

\section{Blood Sampling}

Blood samples were obtained from juvenile Montagu's harriers which had hatched in the Bavarian administrative district of Unterfranken in 2009-2012. In a radius of about $40 \mathrm{~km}$ around the village Volkach $49^{\circ} 52^{\prime} \mathrm{N}, 10^{\circ} 14^{\prime} \mathrm{E}$ near Würzburg $49^{\circ} 46^{\prime} \mathrm{N}, 09^{\circ} 56^{\prime} \mathrm{E}$ Montagu's harriers breed patchily distributed in an intensively used agricultural landscape. The exact locations of breeding sights vary from year to year. During a ringing program, we visited all harrier nests and took blood samples by puncturing the brachial vein of a wing. The blood was stored in an EDTA buffer (10\% EDTA, $0.5 \% \mathrm{NaF}, 0.5 \%$ thymol, $1 \%$, Tris-HCL, $\mathrm{pH}=7.5$ [23]) at $4{ }^{\circ} \mathrm{C}$ until DNA extraction.

Blood samples from adult females were collected during breeding season (beginning of May to end of July 20092012) using a triatomine bug, hidden in an artificial egg. It enabled us to obtain a blood sample from incubating females without having to trap them. This non-invasive method is gaining popularity for sampling sensitive, wild or captured animals [24-30]. Larvae of Dipetalogaster maxima, Uhler 1894 (Heteroptera, Reduviidae) were obtained from G. Schaub (Ruhr Universität Bochum, Germany). They were maintained in plastic boxes in a climate chamber at the Julius-Maximilians-University Würzburg, Germany, at optimal conditions [30] of $27{ }^{\circ} \mathrm{C}$, a relative humidity of $80-90 \%$ and a light period of 13 hours. Only third instar larvae were used for blood sampling. Nearly all of these larvae engorge totally about 4-9 weeks after the moult to this instar (Schaub personal communication).

We received artificial eggs made of synthetic resin from R. Nagel (Institut für Vogelforschung "Vogelwarte Helgo- land", Wilhelmshaven, Germany). The eggs resembled natural Montagu's harrier eggs in shape, size and colour. To place a bug inside, the eggs were divided into two halves. Along the frame of each shell halve small holes $(2-3 \mathrm{~mm}$ in diameter) had been drilled which allowed a bug to reach the harrier but prevented its escape. Both halves could be closed with small magnets attached to the inner sides. We fixed one "bug-egg" per nest to the ground with a $5 \mathrm{~cm}$ long fishing line and a tent peg. With this treatment we made sure, that the breeding harrier could not remove the "bug-egg". At the same time the female harrier was still able to move her clutch. According to the studies on Common terns (Sterna hirundo) $[24,25]$ we placed "bug-eggs" into a clutch between 6:00 a.m. and 12:00 a.m. Before choosing a bug, we tested its willingness for blood sucking by holding a finger in front of it [25]. If a bug erected its proboscis and tried to sting, it was placed into an artificial egg. From a distance we observed the females returning to their nest sites. Since the nests are located in grain fields, it was impossible to watch the behaviour of a female when it was in the nest area. Therefore, we could not observe if and when the female continued incubation. At the beginning of the study we left the artificial egg in the nest for $2 \mathrm{~h}$. As the success rate was too low in the first two years $(25-67 \%)$ we extended this period to at least $4 \mathrm{~h}$, which resulted in a much higher success rate (2011: 83\%, 2012: 89\%). After the bug had sucked blood we retrieved the blood from the abdomen with a syringe and stored it in an EDTA buffer. Each bug, successful or not, had to be killed afterwards to avoid mixing of sample material.

\section{DNA Extraction, 454 Pyrosequencing and Primer Devel- opment}

DNA extraction was carried out following a standard protocol with Proteinase K digestion (Merck, Darmstadt) and phenol-chloroform extraction [31].

We used 454 shot-gun pyrosequencing on a GS Junior sequencer (454 Life Sciences/Roche Applied Science) to create a genomic library of Montagu's harrier, using the GS FLX Titanium Rapid Library Preparation Kit following the manufacturer's recommendations. A single sequencing run of a DNA sample yielded 85,624 usable reads with a total of $>33 \mathrm{Mb}$ of sequence data. Average read length was $391 \mathrm{bp}$. With MSATCOMMANDER version 0.8.1 [32], 448 loci with repetitive STR motives (excluding mononucleotide repeats) could be identified. Primer3 software [33] proposed 156 primer pairs of which 92 were unique.

We chose 42 loci containing at least 10 repeats and tested them for reliability and polymorphisms. 10 Montagu's harrier DNA samples were amplified by PCR under the following conditions: a $25 \mu \mathrm{l}$ reaction volume contained $60 \mathrm{ng}$ of total DNA, $0.4 \mathrm{pmol} / \mu \mathrm{l}$ of each forward and reverse primer, $0.1 \mathrm{mM}$ of dGTP, dCTP and dTTP, as well as $45 \mu \mathrm{M}$ of dATP, 1.5 x PCR buffer (Bioron), 0.15 units of Top-Taq DNA polymerase (Bioron), $1 \mu \mathrm{Ci}\left[\alpha-{ }^{33} \mathrm{P}\right]$-dATP (Amersham Biosciences) and a variable amount of mono-distillate water (to reach a volume of $25 \mu \mathrm{l}$ ). Thermocycling was performed in a Tgradient ThermoCycler (Biometra) starting with an initial denaturing step for $5 \mathrm{~min}$ at $95{ }^{\circ} \mathrm{C}$, followed by 38 cycles of $45 \mathrm{~s}$ at $95{ }^{\circ} \mathrm{C}, 60 \mathrm{~s}$ at $50-58{ }^{\circ} \mathrm{C}, 90 \mathrm{~s}$ at $72{ }^{\circ} \mathrm{C}$, followed by a final extension step at $72{ }^{\circ} \mathrm{C}$ for $10 \mathrm{~min}$ and a cooling step at $15^{\circ} \mathrm{C}$ for storage. PCR products were dena- 
tured at $95{ }^{\circ} \mathrm{C}$ for 5 min and subsequently separated by vertical high-resolution polyacrylamide gel $(5 \%)$ electrophoresis at $65 \mathrm{~W}$ for $1.5 \mathrm{~h}$ that resulted in a run length of ca. $40 \mathrm{~cm}$. After drying the gel, an X-ray film (Hyperfilm-MP; Amersham) was overlaid for 1-2 days for autoradiography and afterwards developed with X-ray developer and fixer (Kodak). 40 of the 42 tested primer pairs produced clear and unambiguous products. 19 of them produced several different alleles and were tested for polymorphism.

\section{Primer Labelling, Multiplex PCR and Fragment Length Analysis}

For high throughput genotyping and loci characterization we arranged the 19 primer pairs in three multiplex PCR systems. In addition to the novel marker set we added some loci originally developed for Eastern Imperial eagle Aquila heliaca, Madagascar Fish-eagle Haliaeetus vociferoides and Northern Goshawk Accipiter gentilis (see results part). Genotyping was carried out with MegaBACE 1000 (Amersham Biosciences) capillary array electrophoresis system.

All forward primers were labelled at the 5' end with one of three different fluorescent dyes to produce fluorescently labelled PCR products. According to the expected allele sizes, we labelled primers with overlapping allele size ranges with different dyes (6-carboxyfluorescein (6-FAM), hexachloro-fluoresceine (HEX) or 5-tetrachloro-fluorescein (TET); produced by Eurofins MWG Operon) and those with non-overlapping ranges with the same dye. As an internal size standard we applied ET-ROX 400 (Amersham Biosciences).

Further development steps included to test the best primer combinations for multiplex PCRs and to find the optimal required PCR conditions for the panels. Multiplex PCR was performed with Type-it Microsatellite PCR Kit (Qiagen) under the following conditions: a total volume of $10 \mu \mathrm{l}$ contained $0.18-0.25 \mathrm{pmol} / \mu \mathrm{l}$ of each forward and reverse primer, $15 \mathrm{ng}$ of total DNA, $5 \mu 1$ of $2 \mathrm{x}$ Type-it Multiplex PCR Master Mix, additionally $0.75 \mu \mathrm{l}$ Q-solution for multiplex set 1 , and a variable amount of RNase-free water (to reach a volume of $10 \mu \mathrm{l}$ ). Thermocycling was performed as follows: an initial denaturing step at $95^{\circ} \mathrm{C}$ for $5 \mathrm{~min}, 28$ cycles of $45 \mathrm{~s}$ at $95^{\circ} \mathrm{C}, 90 \mathrm{~s}$ at $60^{\circ} \mathrm{C}$ for multiplex set 1 and $2\left(58^{\circ} \mathrm{C}\right.$ for multiplex set 3 ) and $72{ }^{\circ} \mathrm{C}$ for $30 \mathrm{~s}$, followed by a final elongation step at $60{ }^{\circ} \mathrm{C}$ for $30 \mathrm{~min}$ and a cooling step at $15^{\circ} \mathrm{C}$.

A 96 well plate for analysis on the MegaBACE was prepared as follows: PCR products were diluted 1:250 with sterile filtrated mono-distilled water. For a 96 well plate we mixed $8 \mu 1$ ET-ROX 400 with $472 \mu 1$ water. $1.2 \mu 1$ of each diluted PCR product was mixed with $4.8 \mu \mathrm{l}$ of diluted ET-ROX 400. A MegaBACE run took $75 \mathrm{~min}$. Electropherograms were analysed with the Genetic Profiler software (Amersham Biosciences). As the program generates decimal numbers for each fragment, manual binning to allele-units was necessary. Therefore, we sorted the decimal numbers of all alleles per locus and plotted them in a diagram. Binning then occurred by identifying significant gaps between fragment sizes [34]. One locus showed frequent deviation from the expected repeat steps and was excluded from further development steps.
STR Characterization, Identity Analyses and Parentage Assessments

We genotyped 100 Montagu's harrier juveniles to characterize our marker set. They were chosen randomly from the whole sample set to avoid the presence of full-sibs in the data set. With Cervus 3.0 [35] we estimated the number of alleles $\left(\mathrm{N}_{\mathrm{a}}\right)$ and calculated Hardy-Weinberg expectations (HWE) with a Bonferroni correction for multiple comparisons as well as observed and expected heterozygosity values ( $H_{\mathrm{obs}}$ and $\left.H_{\text {exp }}\right)$. Polymorphism information content (PIC) and power of exclusion values (PE) for each locus separately were calculated in PowerStats V12 (Promega Corporation 2000). PIC, non-exclusion probabilities for parents, individual identity and sib identity probabilities over the whole marker set were estimated with Cervus 3.0 [35], too. Furthermore we tested for evidence of null alleles with MicroChecker software [36].

In order to test the suitability of the marker set for parentage analyses we genotyped 369 samples from juvenile Montagu's harriers and 197 samples from corresponding breeding females with known mother-chick relationships. The genetic kinships were analysed with Colony 2.0 [37] and compared to the results with known family backgrounds, which we had gained from field work. In a simulated comparison with two other parentage analyses methods (Exclusion-Bayes' Theorem-Christie method and PairwiseLikelihood-FAMOZ) the Full-Likelihood method implemented in Colony 2.0 was nominated as the best one within the range of observed values [38]. Although it is possible to add information about full-sib relationships, we neglected this, because this could have an impact to assignment accuracy. We assumed a polygamous mating system for both sexes, because we collected samples from several different breeding seasons; a fact to be considered according to user guide of the program. Montagu's harriers are supposed to be monogamous in one breeding season but change their partners in subsequent years. Therefore, paternal half-sibs might have been included in the sample set.

Additionally we performed an identity test with the 197 female samples using Cervus 3.0 [35]. These samples were collected over a sequence of four years which enabled the possibility of re-sampling by chance.

\section{RESULTS}

\section{Multiplexing and Loci Characterization}

Using the NGS approach, 16 new polymorphic STR-loci could be identified from Montagu's harrier and characterised. To establish three multiplex- PCR sets (Table 1), the 16 newly developed loci were combined with additional three loci originally developed for Aquila heliaca (locus IEAAAG15) [39], Haliaeetus vociferoides (locus Hvo-02). [40] and Accipiter gentilis (locus Age 5) [41].

In Fig. (1) an electropherogram of a Montagu's harrier sample, amplified with multiplex panel 1 (8 STR-loci), is shown.

Table 2 documents the characterisation of each locus. According to the number of alleles and PIC values, the marker set is highly informative. The mean number of alleles 

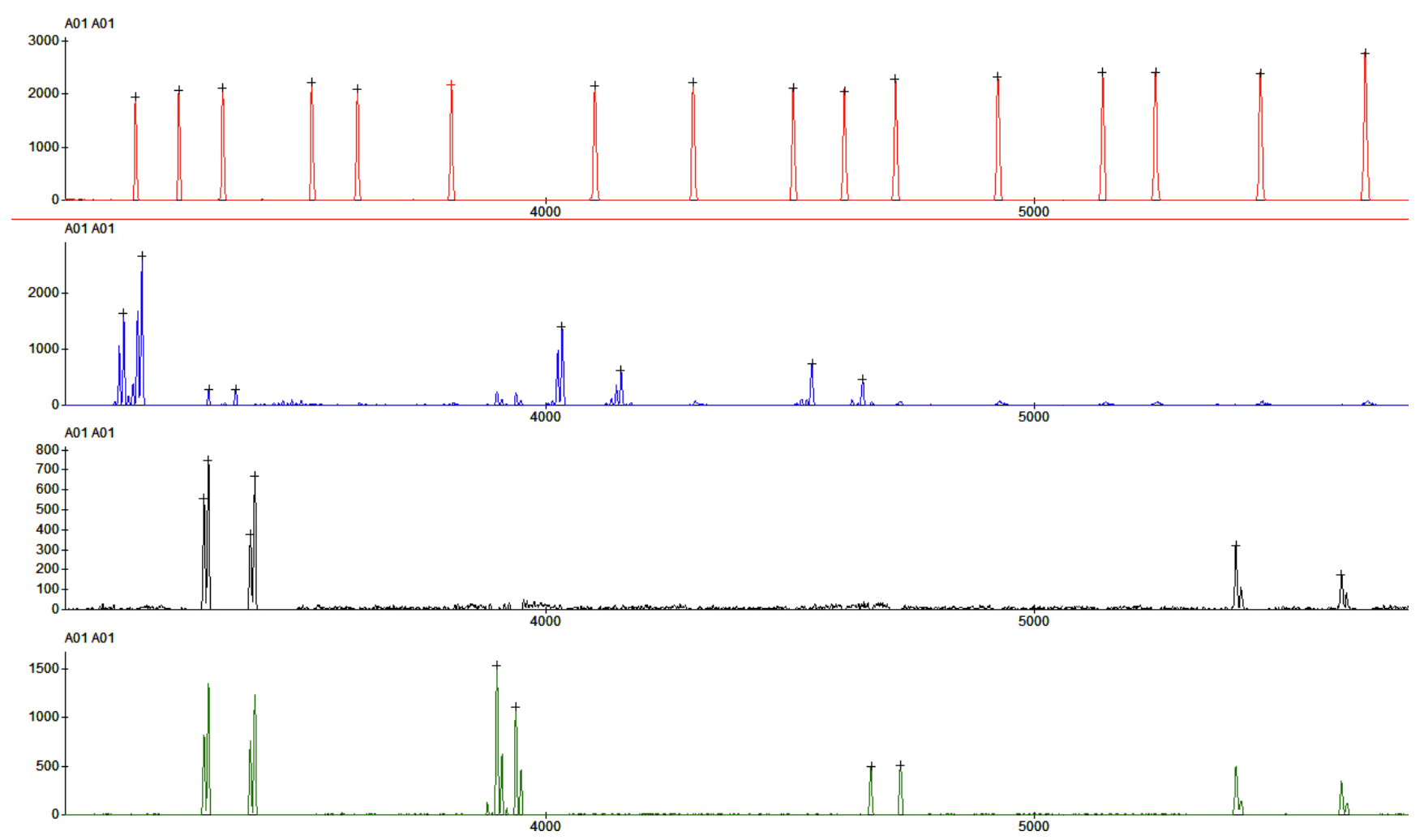

Fig. (1). Electropherogram from the Genetic Profiler software. Genotyping of a Montagu's harrier sample amplified with multiplex panel 1. All allele peaks appeared after a run duration of ca. $60 \mathrm{~min}$. The four different graphs represent the four spectral channels analysed by the MegaBACE instrument. X-axes: signal intensity of peaks; y-axes: run time. Top-trace (red): fragments of ET-ROX 400 size standard. Second trace (blue): four STR-loci labelled with FAM, each with two alleles. Those peaks with a cross on top are allele peaks. Different STR-loci can by distinguished by the proximity of their corresponding allele peaks. Third trace (black): two STR-loci labelled with HEX, each with two alleles. Bottom-trace (green): two STR-loci labelled with TET are located in the middle of the trace, each with two alleles. Both two peaks at the beginning and the end of the run in this trace are identical with the peaks in the upper trace because signals of HEX labelled fragments often extend into the TET spectral channel.

is 8.6 and a PIC calculation across all loci revealed a value of 0.67. Only three loci (MS_Cpyg16, MS_Cpyg29 and Hvo-02) showed PIC values less than 0.50. Micro-Checker revealed evidence for presence of null alleles for locus MS_Cpyg42. Three loci did not conform to Hardy-Weinberg expectations. PE values for single loci ranged from $0.05-0.82$.

\section{Parentage Analysis}

The multiplex marker sets for 19 loci were used to analyse parentage for 369 samples from juvenile Montagu's harriers and 197 samples from corresponding breeding females with known mother-chick relationships (Table 3). The $\mathrm{PE}$ value over the whole marker set is 0.99 . It is obvious that the probability of not excluding an unrelated candidate parent from parentage of an arbitrary offspring is much smaller when the genotype of the related parent is known. In the case of parent pair (NE-pp) analyses it is very unlikely to not find the correct parents for any offspring. Moreover, the confirmation of individual identities (NE-I) and full-sibling relationships (NE-SI) is highly reliable.

An identity test was performed to find adult females that had been sampled more than one time between 2009 and 2012. In total, 38 individuals out of 197 females could be detected more than once. Seven females were sampled three times and 31 females were sampled two times. Their identities could be confirmed unequivocally since they did not show any allelic mismatch. In a second step, we omitted the samples from identical females which were genotyped before. Full-sibships were accurately determined by Colony 2.0 [37] to $97.6 \%$ of all mothers.

\section{DISCUSSION AND CONCLUSION}

Our newly developed STR marker set for Montagu's harrier is highly informative. Although there are two of the new loci that deviated significantly from HWE and another one showed a possibility for null alleles, we could show that the whole marker set is a useful tool for genetic analysis of Montagu's harriers. Indeed, we cannot explain the deviation from HWE for MS_Cpyg04 and MS_Cpyg25, since there is no significant heterozygote deficit or excess. We do not assume biological causes as an explanation, like strong inbreeding or selection for or against alleles, since only two instead of all loci deviate from HWE. In both cases $H_{o b s}$ is slightly smaller than $H_{\text {exp }}$ which could be an indication for "large allele dropout". For both loci it is observed that heterozygotes often show alleles of very different size. A very large allele of a heterozygote could appear too faint for detection, since amplification of sequences is more difficult for larger than for smaller ones [42]. 
Table 1. Three multiplex PCR sets for the amplification of microsatellite loci in Montagu's harrier.

\begin{tabular}{|c|c|c|c|c|c|}
\hline Multiplex Panel & Locus & Primer Sequence $\left(5^{\prime}-3^{\prime}\right)$ & Dye & Concentration $[\mathrm{pmol} / \mu \mathrm{I}]$ & $\mathbf{T}_{a}$ \\
\hline \multirow[t]{12}{*}{ Panel I } & MS_Cpyg01 & F: ACTGAGTATTGATGACTGCTGC & TET & 0.2 & $60^{\circ} \mathrm{C}$ \\
\hline & MS_Cpyg05 & F: GCTTCTGGAGGAGCATCATG & HEX & 0.2 & \\
\hline & & R: TCAGTCCTCCAAGAACCCAG & & & \\
\hline & & R: TGCACCAGGGGAGGTTTAGAC & & & \\
\hline & MS_Cpyg 16 & F: TCTGCCACACTTCTCACAGG & FAM & 0.18 & \\
\hline & & R: TGAGAGGCTGTTGTATCATCTC & & & \\
\hline & MS_Cpyg19 & F: AGTGGCCTAATGTCCTAAACC & TET & 0.2 & \\
\hline & & R: GGTAGTGGTCTGCAGCTTAATG & & & \\
\hline & MS_Cpyg26 & F: AGCCACCTGAAACCCTTTAAAC & FAM & 0.25 & \\
\hline & & R: TCTCAGCTCTCAGTCTTGGG & & & \\
\hline & Age5 & F: ACGTTACAGACACCGATTACTTCC & FAM & 0.25 & \\
\hline & & R: AGCCACGCGTCTGATACTTT & & & \\
\hline \multirow[t]{5}{*}{ Panel II } & MS_Cpyg04 & F: CAGGAGAGCTTCTGGTAGGG & TET & 0.2 & $60^{\circ} \mathrm{C}$ \\
\hline & & R: TGACAGTACTCAGCACCCAC & & & \\
\hline & MS_Cpyg07 & F: CCTGATAGGGCTGGTGTTCTAG & HEX & 0.25 & \\
\hline & Hvo-02 & F: CGTTTATGCTAGGGCTGCTT & TET & 0.18 & \\
\hline & & R: GTCAATGACAAGGCTGAGCA & & & \\
\hline \multirow[t]{12}{*}{ Panel III } & MS_Cpyg29 & F: AAGTCCTAAGCCCAAACACC & TET & 0.25 & $58^{\circ} \mathrm{C}$ \\
\hline & & R: CTATGCAAGGAAGGGTACAG & & & \\
\hline & MS_Cpyg30 & F: AGGTTCTGGCTGTAGGTAGAC & FAM & 0.25 & \\
\hline & & R: TGACTGCTGAAACTGGCAAC & & & \\
\hline & MS_Cpyg31 & F: CTGCCATACTTCTGCCATGC & HEX & 0.2 & \\
\hline & & R: GATGCCTGTACAAGCAACTG & & & \\
\hline & MS_Cpyg33 & F: AGTCGGGTACTCATCACAGC & TET & 0.25 & \\
\hline & & R: GACGACTTGCACTGACAGAG & & & \\
\hline & MS_Cpyg42 & F: GTCTTGAGCATCCCACCTCC & HEX & 0.25 & \\
\hline & & R: GCGAAGTCTGCTAGCACAAG & & & \\
\hline & IEAAAG15 & F: GAGAATAATTTTTGAAAAGCAGTAGG & FAM & 0.25 & \\
\hline & & R: GCTTAGTTGTTCAGAGGACGGTAAG & & & \\
\hline
\end{tabular}


Table 2. Characterization of the STR loci.

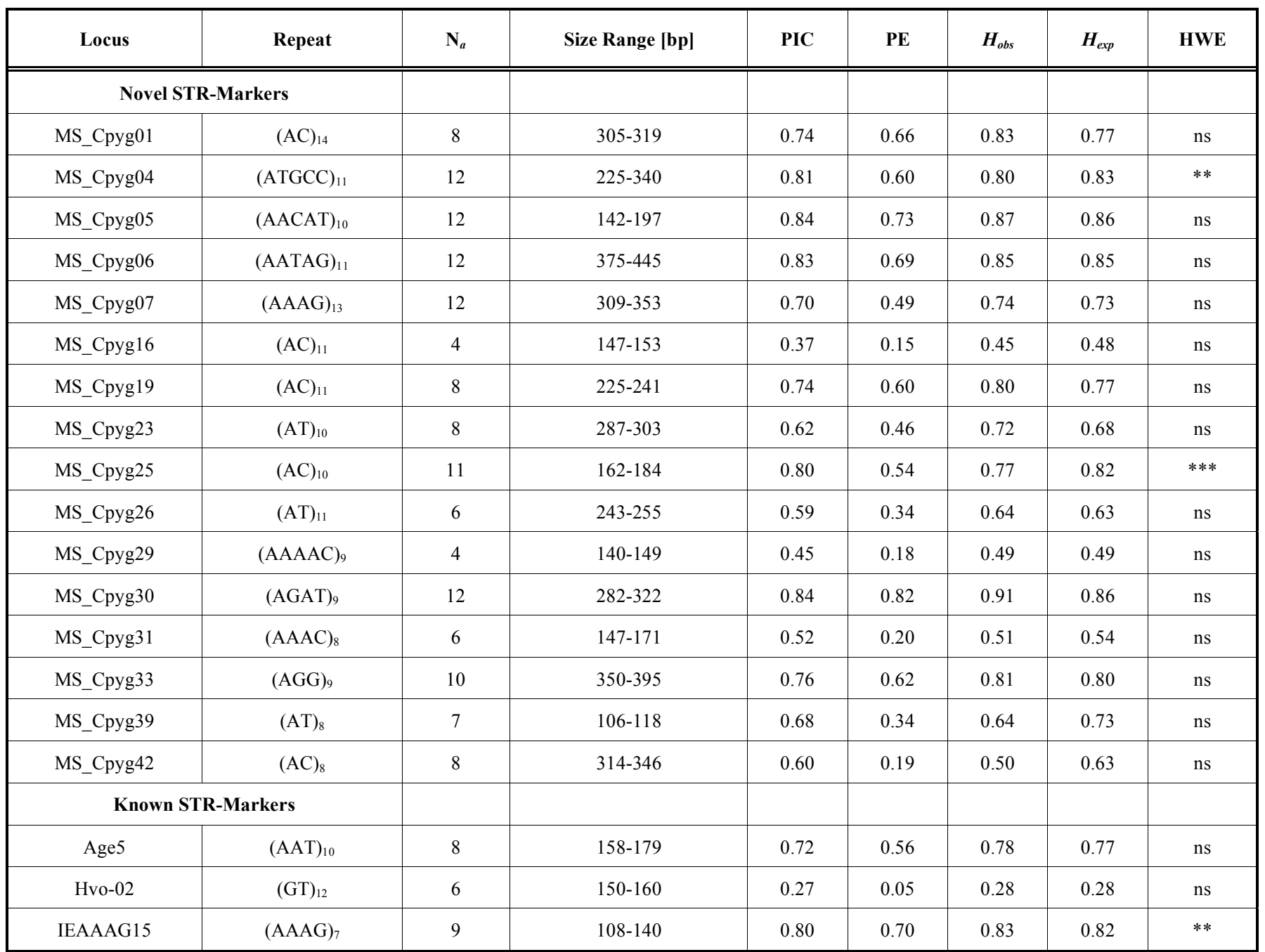

Na: number of alleles; PIC: Polymorphism information content; PE: power of exclusion; Hobs: observed heterozygosity; Hexp: expected heterozygosity; HWE: Hardy-Weinberg equilibrium; ns: no significant departure; *: significant departure at the $5 \%$ level; **: significant departure at the $1 \%$ level; *** significant departure at the $0.1 \%$ level.

Table 3. Parentage and identity statistics across all 19 loci.

\begin{tabular}{|c|c|}
\hline Statistic of Interest & Probability \\
\hline \hline PE $_{\text {all }}$ & 0.99 \\
\hline NE-1p & $0.16^{*} 10^{-3}$ \\
\hline NE-2p & $0.37 * 10^{-6}$ \\
\hline NE-pp & $1.13 * 10^{-11}$ \\
\hline NE-I & $1.53 * 10^{-19}$ \\
\hline NE-SI & $0.80 * 10^{-7}$ \\
\hline
\end{tabular}

$\mathrm{PE}_{\text {all }}$ : power of exclusion for the whole marker set; NE-1p and NE-2p: combined nonexclusion probability for two possible parents when the genotype of the real parent is unknown (1p) or known (2p). NE-pp: combined non-exclusion probability for parent pairs. NE-I and NE-SI: probability to not distinguish between two randomly-selected individuals (I) or full-siblings (SI).

Regardless of the relatively small PE values for single loci the whole set is reliable for parentage tests, as PE is 0.99. Our comparison between known and calculated mother-chick relationships shows that the marker set is suitable to investigate parentage. Our result of $97.6 \%$ is similar to a study in which parentage analysis was simulated [36] and analysed with Colony 2.0 [37]. Under different scenarios they achieved a mean accuracy of $98.4 \pm 4.0 \%$. However, Colony 2.0 did not find the expected mother in $2.4 \%$ (nine chicks out of 369) of all known mother-chick relationships. All nine cases were due to allelic mismatches. They might result from false allele calling or allele dropout. In four cases Colony 2.0 could not match a feeding female with the chick in the nest; In one instance, a female harrier with only one sampled chick was rejected as true mother. In addition, a nest with three chicks was assigned to another female which was not attending the young. These findings appear to be cases of intra-specific brood parasitism, which have not been reported for Montagu's harrier so far, but for some other avian species. Using molecular methods intra-specific brood parasitism is reported for ruddy ducks (Oxyura jamaicensis) [43], American striped cuckoos (Tapera naevia) [44], monk parakeet (Myiopsitta monachus) [45] and many other species, reviewed by Arnold and Owens [46] and Griffith et al. [47] amongst others. Sample interchange could have hap- 
pened, which is very unlikely as well, since the samples of wrongly assigned mothers were collected and isolated in different years.

The three multiplex STR panels will enable us to genotype a large data set of more than 2000 samples of Montagu's harriers from Germany in a cost and time saving way. The new marker set is also valuable for investigations of breeding systems, kinship and family structures. Identity and parentage tests can provide a more detailed insight into the life time reproductive success, population genetics and phylogeography of this species.

\section{CONFLICT OF INTEREST}

The authors confirm that this article content has no conflict of interest.

\section{ACKNOWLEDGEMENTS}

We are grateful to the Landesbund für Vogelschutz in Bayern e.V. and several volunteers for their aid and support during field work. Financial support was provided by the Gerhard und Ellen-Zeidler Stiftung, the Landesamt für Umwelt Bayern and LGFG Baden-Württemberg. Sequencing was financed within the project "GenoSeq" funded by the Ministry of Science, Research and Culture of the Federal State of Brandenburg (Germany) in the EFRE-programme "Science and technology transfer for innovation" (FKZ 80143246). P. H. Becker (Institut für Vogelforschung "Vogelwarte Helgoland", Wilhelmshaven, Germany) provided helpful advice concerning the "bug-method". G. Schaub (Ruhr Universität Bochum, Germany) produced the bugs for us and provided useful information. Thanks go to JuliusMaximilians-University Würzburg, Germany, for using a climate chamber. H. Schäfer (IPMB, Heidelberg) gave helpful advice for manuscript preparation. Hedwig Sauer-Gürth (IPMB, Heidelberg) helped with DNA extraction.

\section{PATIENT'S CONSENT}

Declared none.

\section{REFERENCES}

[1] Clarke R. Montagu's Harrier. Chelmsford: Arlequin Press 1996.

[2] Glutz Von Blotzheim U, Bauer KM, Bezzel E. Handbuch der Vögel Mitteleuropas. Band 4 Falconiformes. Frankfurt: Akademische Verlagsgesellschaft Frankfurt/Main 1971.

[3] Sanchez-Zapata JA, Carrete M, Gravilov A, et al. Land use changes and raptor conservation in steppe habitats of Eastern Kazakhstan. Biol Conserv 2003; 111: 71-7.

[4] Simmons RE. Harriers of the World. Oxford: Oxford University Press 2000.

[5] Arroyo B, García JT, Bretagnolle V. Circus pygargus Montagu's Harrier. Oxford: Oxford University Press 2004.

[6] Koks BJ, Visser EG. Montagu's Harriers Circus pygargus in the Netherlands: does nest protection prevent extinction? Ornithologischer Anzeiger 2002; 41: 159-66.

[7] Arroyo B, García JT, Bretagnolle V. Conservation of the Montagu's harrier (Circus pygargus) in agricultural areas. Anim Conserv 2002; 5: 283-90.

[8] Corbacho C, Sánchez JM, Sánchez A. Breeding biology of Montagu's Harrier Circus pygargus $\mathrm{L}$ in agricultural environments of southwest Spain; comparison with other populations in the western Palearctic. Bird Study 1997; 44: 166-75.
[9] Millon A, Bourrioux JL, Riols C, Bretagnolle V. Comparative breeding biology of Hen Harrier and Montagu's Harrier: an 8-year study in north-eastern France. Ibis 2002; 144: 94-105.

[10] Arroyo B. Breeding ecology and nest dispersion of Montagu's Harrier Circus pygargus in Central Spain. Dissertation; University of Oxford 1995.

[11] Pürckhauer C. Artenhilfsprogramm Wiesenweihe (Circus pygargus) in Bayern - Jahresbericht 2012. Landesbund für Vogelschutz in Bayern e.V. (LBV) im Auftrag des Bayerischen Landesamtes für Umwelt (LfU); Augsburg 2012.

[12] Illner H. Schutzprogramm für Wiesenweihen und Rohrweihen in Mittelwestfalen - Jahresbericht 2011. Arbeitsgemeinschaft Biologischer Umweltschutz im Kreis Soest e.V.; Bad Sassendorf 2011.

[13] Koks BJ, Trierweiler C, Visser EG, Dijkstra C, Komdeur J. Do voles make agricultural habitat attractive to Montagu's Harrier Circus pygargus? Ibis 2007; 149: 575-86.

[14] Butet A, Leroux ABA. Effects of agriculture development on vole dynamics and conservation of Montagu's Harrier in western French wetlands. Biol Conserv 2001; 100: 289-95.

[15] Donald PF, Green RE, Heath MF. Agricultural intensification and the collapse of Europe's farmland bird populations. Proc Biol Sci 2001; 268: 25-9.

[16] Greenwood PJ. Mating systems, philopatry and dispersal in birds and mammals. Anim Behav 1980; 28: 1140-62.

[17] Johnson ML, Gaines MS. Evolution of dispersal-theoretical-models and empirical tests using birds and mammals. Annu Rev Ecol Syst 1990; 21: 449-80.

[18] Liminana R, Garcia JT, Gonzalez JM, et al. Philopatry and natal dispersal of Montagu's harriers (Circus pygargus) breeding in Spain: a review of existing data. Eur J Wildl Res 2012; 58: 549-55.

[19] Wink M, Sauer-Gürth H. Phylogenetic relationships in diurnal raptors based on nucleotide sequences of mitochondrial and nuclear marker genes. In: Chancellor RD, Meyburg BU, Eds. Proceedings of the 6th World Conference on Birds of Prey and Owls; 2003: Budapest, Raptors Worldwide 2004, pp. 483-98.

[20] García JT, Alda F, Terraube J, et al. Demographic history, genetic structure and gene flow in a steppe-associated raptor species. BMC Evol Biol 2011; 11: 1-11.

[21] Sunnucks P. Efficient genetic markers for population biology. Trends Ecol Evol 2000; 15: 199-203.

[22] Jarne P, Lagoda PJL. Microsatellites, from molecules to populations and back. Trends Ecol Evol 1996; 11: 424-9.

[23] Nader W, Werner D, Wink M. Genetic diversity of scarlet macaws Ara macao in reintroduction studies for threatened populations in Costa Rica. Biol Conserv 1999; 87: 269-72.

[24] Arnold JM, Oswald SA, Voigt CC, et al. Taking the stress out of blood collection: comparison of field blood-sampling techniques for analysis of baseline corticosterone. J Avian Biol 2008; 39: 58892.

[25] Becker PH, Voigt CC, Arnold JM, Nagel R. A non-invasive technique to bleed incubating birds without trapping: a bloodsucking bug in a hollow egg. J Ornithol 2006; 147: 115-8.

[26] Thomsen R, Voigt CC. Non-invasive blood sampling from primates using laboratory-bred blood-sucking bugs (Dipetalogaster maximus; Reduviidae, Heteroptera). Primates 2006; 47: 397-400.

[27] Voigt CC, Fassbender M, Dehnhard M, et al. Validation of a minimally invasive blood-sampling technique for the analysis of hormones in domestic rabbits, Oryctolagus cuniculus (Lagomorpha). Gen Comp Endocrinol 2004; 135: 100-7.

[28] Voigt CC, Peschel U, Wibbelt G, Frölich K. An alternative, less invasive blood sample collection technique for serologic studies utilizing Triatomine bugs (Heteroptera; Insecta). J Wildl Dis 2006; 42: 466-9.

[29] Von Helversen O, Volleth M, Núnez J. A new method for obtaining blood from a small mammal without injuring the animal: use of triatomid bugs. Experientia 1986; 42: 809-10.

[30] Stadler A, Meiser CK, Schaub GA. "Living syringes": use of hematophagous bugs as blood samplers from small and wild animals. In: Mehlhorn H, Ed. Parasitology Research Monographs 1, Nature helps? How plants and other organisms contribute to solve health problems, Berlin, Springer-Verlag 2011; pp. 243-71.

[31] Sambrook J, Fritsch EF, Maniatis T. Moleculer clooning: a labaratuary manual. New York: Cold Spring Harbor Laboratory Press 1989. 
[32] Faircloth BC. MSATCOMMANDER: detection of microsatellite repeat arrays and automated, locus-specific primer design. Mol Ecol Resour 2008; 8: 92-4.

[33] Rozen S, Skaletsky H. Primer3 on the WWW for general users and for biologist programmers. Methods Mol Biol 2000; 132: 365-86.

[34] Guichoux E, Lagache L, Wagner S, et al. Current trends in microsatellite genotyping. Mol Ecol Resour 2011; 11: 591-611.

[35] Kalinowski ST, Taper ML, Marshall TC. Revising how the computer program CERVUS accommodates genotyping error increases success in paternity assignment. Mol Ecol 2007; 16: 1099-06.

[36] Van Oosterhout C, Hutchinson WF, Wills DPM, Shipley P. MICRO-CHECKER: software for identifying and correcting genotyping errors in microsatellite data. Mol Ecol Notes 2004; 4: 535-8.

[37] Jones O, Wang J. COLONY: a program for parentage and sibship inference from multilocus genotype data. Mol Ecol Resour 2010; 10: 551-5.

[38] Harrison HB, Saenz-Agudelo P, Planes S, Jones GP, Berumen ML. Relative accuracy of three common methods of parentage analysis in natural populations. Mol Ecol 2013; 22: 1158-70.

[39] Busch JD, Katzner TE, Bragin E, Keims P. Tetranucleotide microsatellites for Aquila and Haliaeetus eagles. Mol Ecol Notes 2005; 5: 29-41.

[40] Tingay RE, Dawson D, Pandhal J, et al. Isolation of 22 new Haliaeetus microsatellite loci and their characterization in the critically endangered Madagascar fish-eagle (Haliaeetus vociferoides) and three other Haliaeetus eagle species. Mol Ecol Notes 2007; 7: 711-5

[41] Topinka JR, May B. Development of polymorphic microsatellite loci in the northern goshawk (Accipiter gentilis) and crossamplification in other raptor species. Conserv Genet 2004; 5: 8614.

[42] Wattier R, Engel CR, Saumitou-Laprade P, Valero M. Short allele dominance as a source of heterozygote deficiency at microsatellite loci: experimental evidence at the dinucleotide locus Gv1CT in Gracilaria gracilis (Rhodophyta). Mol Ecol 1998; 7: 1569-73.

[43] Reichart LM, Anderholm S, Munoz-Fuentes V, Webster MS. Molecular identification of brood-parasitic females reveals an opportunistic reproductive tactic in ruddy ducks. Mol Ecol 2010; 19: 401-13

[44] Mark MM. Host-specific parasitism in the Central American striped cuckoo, Tapera naevia. J Avian Biol 2013; 44: 445-50.

[45] Martinez JJ, De Aranzamendi MC, Masello JF, Bucher EH. Genetic evidence of extra-pair paternity and intraspecific brood parasitism in the monk parakeet. Front Zool 2013; 10(1): 68.

[46] Arnold KE, Owens IPF. Extra-pair paternity and egg dumping in birds: life history, parental care and the risk of retaliation. Proceedings of the Royal Society B-Biological Sciences 2002; 269: 1263-9.

[47] Griffith SC, Lyon BE, Montgomerie R. Quasi-parasitism in birds. Behav Ecol Sociobiol 2004; 56: 191-200.

(C) Janowski et al.; Licensee Bentham Open.

This is an open access article licensed under the terms of the Creative Commons Attribution Non-Commercial License (http://creativecommons.org/licenses/by-nc/3.0/) which permits unrestricted, non-commercial use, distribution and reproduction in any medium, provided the work is properly cited. 